\section{Questión}

Periodismo / Comunicación ISSN 1669-6581
- Av. $44 \mathrm{~N}^{\circ} 676,1^{\circ}$ piso

CP 1900 - La Plata - Argentina

www.perio.unlp.edu.ar/question

Correspondencias de análisis y crítica de medios

Lía Gómez, Carlos Vallina, Juan Manuel Bellini y Néstor Andrés Caetano Madrigal.

DOI: https://doi.org/10.24215/16696581e334

\title{
Correspondencias de análisis y crítica de medios
}

\section{Media analysis and critical correspondences}

Lía Gómez

Profesorade la FPyCS/UNLP y de la Escuela de Arte/ UNQ, critica cultural de radio UNLP y TV UNLP.

Carlos Vallina

Profesor Emérito de la FPyCS y realizador y crítico cultural en radio UNLP.

Juan Manuel Bellini

Periodista. Docente de la cátedra Análisis y Crítica de Medios FPyCS/UNLP. Trabaja en el Programa de Justicia por

Delitos de Lesa Humanidad.

Néstor Andrés Caetano Madrigal

Licenciado y Profesor en Comunicación Social FPyCS/ UNLP. Docente e investigador.

Cátedra de Análisis y Crítica de Medios y equipo de investigación de la UPID en arte y política de la FPyCS.

1. Verdad/Consecuencia

Carlos Vallina

8:45 de la mañana del día 1ํ de mayo de 2020 tocan el timbre, no esperamos a nadie, no hay visitas previstas, no es posible ello, leemos diarios de la semana porque hoy no hay edición, menciono esto porque no entiendo la ausencia de los periódicos impresos cuando es un servicio esencial, está contemplado que se paga doble en caso de trabajar, y no me es lo mismo acudir a la pantalla, para nada, pero agradezco que reviso los acumulados, con subrayados, marcas, y en particular los suplementos culturales. Vuelvo a la puerta de casa y resulta ser un adolescente con un escobillón gastado que le sirve de bastón mientras indica musitando su intención barrer las hojas acumuladas en la vereda a cambio naturalmente de alguna "ayuda " dice ,y en rigor lo tomo como una tarea que implica abonarla. Dice que deja librada a mi criterio la suma, y al regresar al interior para buscar la contribución le comento a mi esposa y me suelta la frase "tiene dignidad". Le llevo una cantidad que estimo razonable y 
antes de volver a los diarios viejos observo que comienza a llevar las hojas hacia el cordón, es apenas un instante porque no quería ejercer una vigilancia que hubiera merecido el repudio de Foucault y de varios intelectuales que son protagonistas de las discusiones libertarias de las últimas décadas.Pero,al salir un rato después, compruebo que se había marchado y que todo está como era entonces," la casa., la calle, el río " ( mi primaria) y el joven ya no estaba y las hojas permanecían doradas y quietas. Nuestro comentario fue, no tiene, ni es posible que la tenga de modo espontáneo, principios, ética, conciencia de sus actos .No fue sincero, utilizó un plan sencillo, mintió. Sabemos que su responsabilidad está basada en la inocencia de la necesidad. Pero hay un factor que en términos políticos me afecta personalmente, como histórico militante, caracterizado como subversivo por los servicios de inteligencia de las dictaduras y gobiernos proimperialistas y patronales siguiendo el lenguaje de ese tiempo, y que es que un ser oprimido, pobre, marginado, utilice las estrategias de la clase dominante. Vino de inmediato en esta reseña una palabra central en nuestro léxico de la generación:

\section{Concientización.}

Hemos visto la pequeña batalla de los intelectuales europeos, sus pronósticos derivados de la observación de la pandemia. La sopa de Wuhan, los anuncios de los más enfervorizados sobre el fin del capitalismo, las aseveraciones sobre que nada será igual una vez superada la misma, y también los rechazos a esta posiciones, la advertencia acerca de que la situación inmediata a la aparición de este ataque de la naturaleza a la fragilidad de la vida humana no variará, solo se verá estremecida, desconcertada y humillada. "Siempre me ha resultado más fácil y más placentero escribir ficción que escribir ensayos. La ficción se escribe mientras se escribe y uno elige y desecha lo que sirve (o no sirve).... mientras que en un ensayo uno tiene que tratar que la prosa soporte lo que uno vino a decir...Se escribe lo que se ha pensado antes y ese es siempre un problema, porque el lenguaje está hecho para que uno piense mientras lo usa de modo que antes de escribir un ensayo uno debe desarrollar las ideas, tener un plan." (Ricardo Piglia.Un día en la vida. Los diarios de Emilio Renzi.)Cito a Ricardo, y me permito nombrarlo así por la cercanía inicial en la ciudad de La Plata, cuando ambos estudiábamos y militábamos y sentíamos la libertad de una generación que había adquirido una nueva conciencia generacional. Por corrientes de la Historia nacional y mundial, por transformaciones culturales, por desgarramientos sociales y políticos, nos apropiamos sin contratos previos de una voluntad 
de intervención en todo lo que estuviera a nuestro alcance. Arte,literatura,cine en particular, en las funciones que los que estudiábamos en la escuela superior de bellas artes descubríamos como si fuéramos los primeros críticos del mundo, uniendo las pasiones más diversas, como las obras literarias, las exposiciones plásticas, las asambleas, el encuentro con zonas proletarias, las primeras publicaciones de revistas, notas, artículos que diseminábamos con la certeza de nuestras convicciones, sujetas a debates interminables, mediadas por el erotismo que nos producían las libertades que se comenzaban a manifestar ya no solo como en 1918,sino porque la experiencia política de nuestro pueblo, de las masas de trabajadores ,de profesionales, de estudiantes, se había colado en la sangre de jóvenes varones y mujeres que sentían la necesidad de la acción, de la lucha, del estudio, de la confianza en nuestras propias fuerzas. Fue el 60 así de simple, que anunciaba el 68 y los setenta. En este marco, el Plan no es otro que redefinir una vida verdaderamente justa y digna. O quizás debamos decir que no hay un Plan, y que nuestros ensayos antes y ahora se parecen más a un conjunto de ficciones narradas con la contundencia de una supuesta verdad. Hermosa palabra tan vapuleada hoy en la circulación de reclamos sobre su validación.

Michel Foucault es uno de los intelectuales que ha sido central en el reconocimiento de las figuras que no dominaban la primera mitad del siglo $X X$,y cuyos conceptos se debaten y utilizan para cuestionar las dominaciones no visibles, las encubiertas y postergadas, indicaba en un seminario denominado "El coraje de la verdad"(1983-1984) lo siguiente: "Hablar franco, de la parrhesía como modalidad del decir veraz...sería igualmente interesante analizar, en sus condiciones y sus formas, el tipo de acto mediante el cual el sujeto, al decir la verdad se manifiesta, y con esto quiero decir, se representa a sí mismo y es reconocido por los otros como alguien que dice la verdad".

Los manifiestos dominaron la primera mitad del siglo XX, uno de ellos derivado del de Marx y Engels entre otras expresiones, el de la Reforma Universitaria decía en 1918:

"Hombres de una República libre, acabamos de romper la última cadena que en pleno siglo XX nos ataba a la antigua dominación monárquica y monástica. Hemos resuelto llamar a todas las cosas por el nombre que tienen"...Los dolores que nos quedan son las libertades que nos faltan. Tal pronunciamiento es de alguna manera corregido por el cordobés del Cordobazo Diego Tatián que nos hace reparar que el término reforma se refería a los estatutos de la universidad, pero que el concepto iba más allá: "Creemos no equivocarnos, las resonancias del 
corazón nos lo advierten. Estamos pisando una revolución, estamos viviendo una hora americana."

Sábado 2 de mayo (cuarenta y cuatro días de cuarentena) 8:45 has.

Mientras preparo el mate enciendo una radio al azar, quizás sea bueno que mi portátil tenga anulado el dial, y escucho una entrevista a Luis Chitarroni,gran lector,editor,autor, que menciona que su gran temor es la desaparición de los libros en papel, reflexiono con los otros oyentes invisibles seguramente tocados por esa posibilidad y sin embargo estoy seguro que será improbable que olvidemos las bibliotecas físicas, las ferias, y todos los modos de intercambio de las joyas ( $y$ de las otras) y sigamos acunando los volúmenes tangibles. Luego una sorpresa, al finalizar ese programa de la primera mañana, anuncia otro, el de la revista Crisis. Versión sonora, allí una de la codirectoras explica las diferentes etapas de la publicación, desde el inicio en los setenta, la transición democrática y esta última que creo haber escuchado que lleva más de cuarenta números en marcha. Columnistas y conductoras mujeres y un varón en buena armonía unidos por sus dos temas del día, el acuerdo de la CGT y la UIA para bajar el salario un $25 \%$ a los trabajadores .Y luego la situación en las cárceles...Buena decisión de las autoridades de Radio Nacional de albergar estas vinos nuevos en odres viejos.

El concepto "revolución" que dejó la escritura de Deodora Roca y la triunfante generación de jóvenes reformistas, determinó que recordara el día que se presentó en la Facultad de Periodismo y Comunicación Social la Tesis de Maestría de Gabriela Esquivada "Noticias-De los Montoneros. La historia del diario que no pudo anunciar la revolución". Ese día compartí el jurado evaluador con el maestro Nicolás Casullo, con el cual había tenido una discusión en una ocasión anterior donde componíamos una mesa redonda sobre los medios y la democracia. Todavía estaba Mariano Grondona ejerciendo su constante presencia en la televisión además de sus editoriales en La Nación, y confrontamos sobre el alcance de una institucionalidad que "obligó" al intelectual orgánico (revisemos su clara indicación en muchas notas, de que su verdadero enemigo se llamaba A.Gramsci), a ir al primer piquete en Cutral Có y a la Carpa Blanca. El sentido del debate era que para mi había que intervenir en la pantalla como militantes e intelectuales y coexistir con el mencionado. El maestro Nicolás enardecido negó que se pudiera ni siquiera pensar en ello.Verbistky había estado en Tiempo Nuevo y fue a disputar espacio en el terreno periodístico. Casullo fue tajante, y creo que su reacción tenía la 
misma fuerza, más allá de la consecuencia de su crítica, y de su fogoso temperamento, del artículo que un tiempo más tarde conocí. Me refiero a lo publicado en Pensamiento de los Confines como número 23/24 en abril de 2009 llamado Memoria y Revolución. Su extensa nota, profunda, plagada de referencias y conclusiones se encuentra atravesada por la Historia, convoca a Sarmiento, a Cooke y por supuesto a la lucha armada de los setenta junto a una revisión crítica de las experiencias de ruptura en Europa. Su caracterización conlleva adjetivos tales como frustrada, clausurada, traicionada, fallida.Su análisis, profundo y fundado, revisa las contradicciones centrales del problema, y escribe por ejemplo "discutir la revolución no es reponer lo revolucionario. No discutirla es ahuecar neuróticamente el pasado...

Ya que estamos citemos el manifiesto histórico "Todo lo sólido se disuelve en el aire, todo lo sagrado es profanado y los hombres al fin, se ven forzados a considerar serenamente sus condiciones de existencia y sus relaciones recíprocas."

Para eso sirve y retomo la Tesis mencionada y la reunión evocada. Allí casullo dijo que el diario Noticias contenía el staff más profesional, lúcido, inteligente y comprometido del país pero que estaba dirigido por burócratas autoritarios a los que nos les interesaba comprender la riqueza de ese capital simbólico.

Dice la Tesis (Sudamericana, 2010, 31) "Noticias apareció con el propósito de convertirse en un diario peronista que funcionara como herramienta en la lucha para la liberación nacional."Gelman, Walsh, Urondo, Verbitsky, Roqué, Moreau, Perrota, y varios más, todos destacado militantes, y periodistas de alto nivel, con la mayor amplitud mental y cultural que se pueda concebir .Así fue sin embargo el tiempo de "combate, dolor y derrota (H.V).

En 1905 se produjo una revolución popular en Rusia, su mayor intérprete la definió como un "ensayo general". El siglo albergaría revoluciones y contrarevoluciones, tan feroces las segundas que arrojarían el fascismo como caricatura de la modernidad. Aquí llegó tarde, como todo lo centralizado por lo europeo .pero también como respuesta a los movimientos transformadores que culminaron en el peronismo entre otros propiciadores de cambios sustanciales para las masa oprimidas.

¿Porqué los intelectuales, periodistas, académicos, militantes mencionados? ¿Porque la cuestión de la verdad?

El hablar franco, no es solo la descripción objetiva del mundo, las conexiones, la urgencia, el archivo, el estilo, el público, las tecnologías, la circulación de los datos; es antes que nada 
adopta un punto de vista y luego de aprobarlo como los del 18 "con el corazón", llevarlo a su más alta expresión gnoselógica.Y ese sentido de la verdad, desde la modernidad en adelante, tiene un protagonista y un eje en el pueblo y los trabajadores.

Maurizio Lazzarato responde a través del texto "El capital odia a todo el mundo" (2020), señalando que con el liberalismo culmina todo un ciclo de luchas y revoluciones. Que los últimos cuarenta años han sido puramente defensivos. Que el pensamiento filosófico del 60/70 no pudo renovar el concepto de lucha de clases. Que la salud pública, un dispositivo biopolítico por excelencia se encuentra completamente investida por el capital privado. Que el problema es el paso de la lucha de clases en sentido singular a la lucha de clases en sentido plural. No se ha logrado poner en crisis a la máquina capitalista. Y que los indicadores más prometedores para una auténtica revolución no vienen, precisamente del norte del mundo. Y que en definitiva lo que Foucault nunca comprendió, como casi la totalidad del pensamiento filosófico es la naturaleza del capitalismo en general y del neoliberalismo en particular.

Neoliberalismo que en rigor comenzó con el asesinato del Salvador Allende, con los golpes de Estado en Sudamérica, con los Chicago Boys y Martínez de Hoz y el Terrorismo de Estado, mientras Europa reclamaba la deudas que nos había impuesto junto con su socio anglosajón el FMl y la flota inglesa y los aliados locales.

Polémico, en mundo de ideas que anulan a sí mismas, que se han parapetado en negar la complejidad de la Historia, la memoria, la praxis social y sus urgencias permanentes como el Covid19.

Revive ante mi " No intenso agora" film cruce entre relato,documento,reflexión subjetiva, revisión icónica y sensibilidad orientada a pensarse no como un presente dominado por un universo Ciborg maquínico y productor de subjetividades secuestradas, sino porloq eu está sucediendo en estos días, donde los seres sociales se vinculan en la inmersión de sus relatos familiares, en la presencia de aquello que ya no está pero no desaparece, que persiste: "No siempre sabemos lo que filmamos", dice la voz en off, enunciado su posición y exponiendo su capacidad de desclasificar el protocolo de lectura de quien hubiera tomado esas imágenes. Operación que repetirá a lo largo de todo el filme. Salles interroga a las imágenes en sus latencias, en sus síntomas, pone al descubierto el inconsciente que las habita, no las despoja de sus fantasmas, de sus espectros. Por el contrario, los convoca, los interpela, los enfrenta. Expone su mirada a las supervivencias (Nachleben) que las habitan. Este concepto que Didi- 
Huberman recupera de Aby Warburg, "expresa los rastros y expresa el trabajo del tiempo en la historia. Nos hace acceder a una materialidad del tiempo a la que Benjamin presta atención en los vestigios, en los"despojos de la historia" (Cecilia Vallina-Un ejercicio íntimo y político ante las imágenes).

Esta obra recorre documentales de la década del 60, fragmentos familiares de paso reducido, y transita "serenamente" pero con un estremecimiento compartido, el viaje de exilio de sus padres que lo llevaron muy niño a la capital de mayo del 68,París.Las fotos, las películas, las grabaciones televisivas nos ponen junto a su discurrir oral ante aquellos momentos en los que se puede observar lo que Moreira Salles indica como lo que más lo conmueve, y nos presenta el cortometraje "Morir a los treinta años", en blanco y negro, donde ante una mesa despojada, los dirigentes de aquella insurrección, entre los que se encuentra Recannatti,riendo,complacidos de su gesta, alegres, dulcemente impertinentes, celebrando con su sola presencia ese corte del flujo hipócrita de las democracias formales. También se puede ver el momento en la Sorbona cuando "por primera vez, un profesor es interrogado e interpelado por un estudiante", siendo este Cohn Bendit y el maestro, no otro que Sartre.

Si la verdad no es una objetividad disecada, una momia aparencial, un museo o un archivo, y si el ejercicio de la crítica, de las crónicas, de los testimonios, de las interpretaciones son tomas permanentes de posición ante la injusticia, la desmemoria, la opresión, la violencia contra los indefensos, la miseria planificada, el desprecio y la humillación, entonces el periodismo es militancia.

De allí, perturba, que la dirigencia del campo nacional, popular, democrática y social se sorprenda del papel reaccionario de los medios dominantes, de sus maniobras de sus ataques a toda acción que recupere los alientos de las revoluciones supuestamente fracasadas, de las transformaciones detenidas, de los luchadores y luchadoras, que no hicieron más y nada menos que exponer sus vidas, libertades, familias aunque el triunfo y la ausencia de errores no estuvieran garantizados.

Me permito entonces citar a Mario Goloboff, escritor, poeta e intelectual en su nota de Pagina 12 del día 20 de abril: "Que me disculpen los heterodoxos ,los nuevos cientistas,los muy modernos renovadores del dogma, los vigilantes del pensamiento antitotalitario:en tanto que haya clases y por consiguiente lucha, las cosas, pasada esta pandemia seguirán igual(o peor).Hasta que haya un tope y al fin se junte todo, en un momento, en un período, en que los 
de abajo no quieran más, y los de arriba no puedan más. $Y$ todo empiece realmente a sacudirse. Mis visiones llegan hasta ahí. No soy un previsor ni un anticipador ni mucho menos un vaticinador de nuevas sociedades. Me queda demasiado grande."(2020). Hasta aquí mi intervención.

\section{Apuntes Platenses}

\section{Lía Gómez}

En 1929 Raúl Scalabrini Ortiz suplantó a Roberto Arlt en el diario El Mundo con una columna titulada "Apuntes porteños"; como en las Aguafuertes del autor del Juguete Rabioso, Scalabrini Ortiz relata las vivencias de la vida cotidiana de una ciudad en plena transformación cultural acarreada por las vanguardias de los años 20, pero también sujeta a la Gran Depresión del 29. Por esos mismos años (entre 1928 y 1930) publica también sus columnas en el diario La Nación. El 16 de enero (1929), se divulga "Las delicias del Teléfono", un título sugerente para una tecnología nueva que emergía como elemento de modernidad. Cuenta allí, las conversaciones entre Antonio Cutrin, "mucamo" de una casa de la calle "Las Heras al 2371" que eleva una queja de su "patrón", a la Compañía de Unión telefónica por la falla del servicio. El texto termina con la siguiente indicación: "Pasó un día, pasó otro, pasaron varios. Con creciente mal humor el abonado repitió la solicitud (...) las voces invisibles procedian formulando promesas, pero el aparato continuaba mudo (...) ¡Qué me van a hacer caso, si no acatan los terminantes mandatos del gobierno, y a pesar de la caducidad de la sobretasa de cinco pesos, la compañía prosigue manteniéndola en la lista de sus tarifas" (Scalabrini, 1929 2017, 115)

Ya en ese tiempo, las telecomunicaciones, el Mercado y el Estado formaban parte de la mirada acida del autor sobre los procesos en la vida cotidiana. Como vemos esta relación tan puesta en boga a través de la aceleración de la tecnología digital no es nada nueva.

Otra cosa llama la atención de estas notas, que se replican en los meses con títulos como "Los perjuicios del teléfono" (26 de octubre 1928) y "Teléfonos de una nueva sensibilidad" (20 de febrero 1929); y es la vinculación entre el avance de la tecnología de las comunicaciones a distancia y las transformaciones en la sensibilidad. A partir de la llegada del aparato con la voz del otro lado, las vinculaciones sociales no fueron las mismas en su articulación de espacio tiempo. Por supuesto, podemos indicar lo mismo del tranvía, el tren, y todos los transportes que 
facilitaron el camino, pero no es eso lo que ahora nos interesa. Salvo por una palabra que nos une con el presente: Plataforma.

Una plataforma es una superficie plana, horizontal que sirve de apoyo para algo o alguien. En las estaciones de transporte (cualquiera fuere su especificidad y su tiempo) las plataformas son aquellas que indican la entrada y salida de vehículos. Es también donde los y las pasajeras esperan, se organizan, empiezan su recorrido. Este término anclado en la contemporaneidad para definir los entornos digitales que albergan varios elementos, es también interesante de ser pensado y vuelto a significar.

La plataforma del desarrollo del teléfono es el inicio de un viaje donde la comunicación se torna central para la superficie de base que nos sostiene. Sin duda, desde la misma indicación de que el lenguaje es nuestra única posibilidad de expresión en todas sus formas posibles, pero también en la conciencia en que las tecnologías son una extensión de las prácticas humanas. A principios del año 2000, una publicidad fue la estrella de la televisión. Walter (Daniel Hendler) de Telefónica, donde un joven volvía del pasado y se enfrentaba a la telefonía móvil posible, al inicio de internet, y demás. Ineludiblemente no podemos dejar de mencionar estos avances en el marco del neoliberalismo brutal de los 90 y el estallido del año 2001.

Este salto temporal del 29 a I 2001 es arbitrario y en el recorrido espacio temporal podríamos contar un montón de otras historias, sin embargo, la crisis del 29 que azotó a la argentina como a a nivel mundial, también se produjo en escala nacional en esos años de fines del gobierno de De la Rúa.

Es conocida la historia que inicia en 2003 , el desarrollo de las telecomunicaciones con ARSAT, y el proyecto de regulaciones en los medios masivos. Dice Sergio Caletti, "la noción de soporte queda reducida a una cierta forma de concebir el desarrollo tecnológico, y deja sin peso la contextualización de los contextos, en lo que esas tecnologías no solo aparecen y se expanden, sino sobre todo a sus contextos de uso" $(2019,107)$.

Los imaginarios en los que hoy vivimos la pandemia del COVID 19, se estructura en esta línea de tiempo, donde los modos y acceso a la comunicación a través de la tecnología son definiciones históricas, culturales, mercantiles, políticas y sociales. No podemos pensar solo una de estas aristas. En todas ellas el teléfono celular es protagonista. ¿Qué diría hoy el personaje de Hendler? 
Ya lo indicaba Jonas Mekas en sus Cuadernos de los sesenta, que fueron escritos entre 1958 y 2010: "Uno debe mantenerse abierto, escuchar atentamente y jamás hacer concesiones: esa es la condición para ser absolutamente moderno, lo cual significa estar absolutamente vivo" $(2017,21)$. En ese relato, de escuchar, de tratar de comprender, de reflexionar y de sentir las desigualdades aún vigentes en nuestra sociedad, es que indicamos junto a Herzog que "la vida está mortalmente encendida o mortalmente apagada" (2016,70), eh aquí la muerte y la vida como contraposición también de estos tiempos.

Escribí en otra nota al calor de la inmediatez de las reflexiones en cuarentena lo siguiente: "Casi como un juego de TEG asistimos a cuántos países son tomados y de qué modo por el virus como un objeto amorfo y extraño. Pareciera competirse por la imagen de un Estado protector, salvaguarda de las vidas humanas, que reconstruye en el mejor de los casos, un sistema de salud, apropiado por lógicas del capitalismo tan cuestionado" (Gómez, 2019, s/p). Visibilizamos estas estrategias a través de los medios, radiales, televisivos, gráficos, digitales (como vemos ninguno aún extinto), las plataformas permiten una convivencia. Sin embargo, Michel Serres sostiene "el mundo cambió tanto que los jóvenes deben reinventar todo: una manera de vivir juntos, instituciones, una manera de ser y conocer" $(2016,1)$. Nos preguntamos, ¿no fue necesario reinventar la manera de vivir, de ser y de conocer en esas vanguardias de los años 20 que relata Scalabini o Arlt? ¿no fue necesario un modo nuevo de vivir como proyecto en las luchas de los 60 y 70 ? ¿no fue necesario repensarse en los 80 , o reinventarse luego de los años 90 ? Los jóvenes siempre buscan un nuevo modo y de allí nuestra esperanza en el futuro en ellos y ellas. "Pulgarcita" como llama Serres a esta nueva generación, es aquella que mira el mundo a través del dígito de los dedos sobre las pantallas, pero estamos seguros/as que también esa lectura es necesaria como nos dice Caletti de comprenderla en su tiempo. Efectivamente, las prácticas se han ido transformando de eso se trata la vida de la imaginación humana, pero eso no implica que las redes sean los "nuevos aparatos ideológicos" como algunos sostienen.

En ese vaivén de lecturas y escrituras, de intercambios casi a modo de correspondencias, es que compartimos estas líneas y las que siguen sobre los medios. Como dice Oesterheld: "También los indios de américa tuvieron éxitos parciales, contra los conquistadores españoles...no se olvide que los cascarudos, no son los verdaderos enemigos" 
Las notas a continuación son parte de ese cotidiano que nos atraviesa como todo diario, cuaderno o bitácora. Allí vamos con la certeza de que la pregunta por el sentido siempre es la mayor apuesta.

\section{La cuarentena en grageas}

Juan Manuel Bellini

En el transcurrir de estos días, la correspondencia digital nos permite seguir pensando colectivamente, con una militancia hacia el individualismo, lo colectivo siempre asoma en la necesidad de la comprensión del mundo. Compartimos artículos, films, fragmentos, poesías, imágenes y en nuestra mirada sobre los medios nacen estas líneas:

De una manera distorsionada, rememoramos una de las secciones de la revista Humor denominada "Los insufribles" unas grageas donde en un párrafo se cuestionaba lo que hacía más difícil la vida en cada quincena. Como pequeño homenaje a esta sección, que podría ser la precursora del twitter, hacemos un breve repaso por postales de estos días:

- $\quad$ Ser policía no se aprende solo en la Vucetich, se puede ejercer la profesión de manera amateur. Vecinos en balcones señalando a un posible transgresor del aislamiento. Videographs indicando un número de teléfono para denunciar al infractor. Los grupos de whatsapps de las alarmas vecinales al pie del cañón: "gente, hay un muchacho en la vereda ya estuvo esta mañana debe ser algún en situación de calle" "es uno que lo echó la mujer", "llamá a la policía, debe ser el que anda desde ayer que lo corrieron de la casa totalmente borracho", "recién vi a un flaco tomando cerveza en la esquina. Balbuceaba algo". "URGENTE: están asaltando a domicilio con Orden Judicial, conocen hasta tu número de DNI". "ADVERTENCIA: una cosa nueva que circula ahora. La gente va de puerta en puerta entregando máscaras. Dicen que es una nueva iniciativa del gobierno local. Le piden que se lo ponga para ver si le queda bien. Está empapado con químicos que te dejan sin aliento. ¡Entonces te roban!”. Todo esto totalmente sic, sazonado con deseos de felices pascuas, noticias sobre la aparición de un gatito perdido y la iniciativa de hacer sonar la alarma a las 21 horas en honor a los médicos y enfermeros.

- La reprimenda sexual. La noticia de un infractor al que la policía lo sorprendió cuando iba en busca de travestis. Así presentaban la noticia, hacían mucho hincapié en que eran travestis. O el policía mendocino sorprendido teniendo relaciones sexuales en un automóvil con 
su novia. La satisfacción colectiva: fue sancionado. No generó el mismo nivel de indignación otro tipo de "excesos" policiales.

- Una alegría para Beatriz Sarlo. El Covid 1919 "tiene una ventaja enorme, los argentinos vamos a dejar de darnos besos". Releyendo "Vivir afuera" de Fogwill, esa interesante pintura sobre la década del ' 90 puede ir en auxilio de Sarlo con este párrafo: "ahora hay una epidemia de saludarse con besitos. Antes lo hacían los sindicalistas, después se contagió a los artistas de televisión y ahora empieza a infectar al cuerpo médico municipal". Narra, entre otras historias, la expansión del HIV y nos sirve también lo que escribía Fogwill en 1998 para traspolarlo al 2020 en la discusión entre EE.UU. y China: "ellos ahora dicen que en el Pentágono jamás incubaron un proyecto de guerra biológica que contemplase la interrupción de la inmunidad obstinada de los cuerpos enemigos".

- Gerardo Rozín teniendo la oportunidad de entrevistar al Presidente e interrumpirlo todo el tiempo. Decía con malicia el director italiano Dino Risi sobre otro grande, Nani Moretti, algo así como "correte que quiero ver la película", ya que Moretti suele aparecer bastante en sus films. Se podría utilizar la frase para Rozín "callate un poco, quiero escuchar al Presidente".

- $\quad$ Estar todo el día conectado y perder media hora en los grupos de Zoom hasta que al final todos podemos escucharnos, se va convirtiendo en un clásico virtual.

- Los foros sobre la crisis del capitalismo y las nuevas oportunidades que presenta una pandemia que mata de a miles. Lo contradictorio a la luz. El pedido de trabajar más, la no separación entre trabajo y hogar, los que se quedan sin ingresos, la pobreza que crece y mucho, las megaempresas que aprovechan para despedir, el descubrimiento recién ahora de la situación infernal en las cárceles.

- $\quad$ Al principio de la pandemia la jactancia sobre "Ja, cuánto hace que no aparece Espert en televisión". Dice el viejo dicho que va tanto el cántaro a la fuente que... aparece Espert y su mensaje es: ya que los empleados públicos no están trabajando, que le descuenten a ellos. En la última elección presidencial no superó un piso digno, sería un trabajo sociológico interesante de cualquier manera la investigación de cuántos de los que lo votaron (o que se subyugan con sus apariciones televisivas o las de Javier Milei) son empleados públicos. Quienes en realidad sí trabajan, actualmente en sus domicilios.

- $\quad$ El periodismo de guerra no descansa. El pase Jonathan Viale - Eduardo Feinmann, la sonrisa sobradora de Nico Wiñazki, las indignaciones de Osvaldo Bazán. Es tanto el contraste 
que hacen parecer a programas como "Polémica en el bar" o "Intratables" como espacios de pensamiento elevado, de debates entre tribunos.

- $\quad$ El portal de yahoo que durante los cuatro años de macrismo informaba sobre noticias curiosas en Australia o Canadá, vuelve a la carga y los enemigos son más o menos siempre los mismos: Cristina y Kiciloff.

- $\quad$ Como si fuera poco, en medio de la pandemia se fue Luis Majul de América (sí, el mismo de los recién nombrados J. Viale, E. Feinmann, sumémosle a Etchecopar, Reato). Lo presentó como un atentado a la libertad de prensa. Revisando su libro sobre Lanata escrito en 2012, en la página 177 hay un reportaje que Majul le hace Verbitsky. Verbitsky le dice que Lanata lo echó de su programa de televisión por presión de Manzano y entonces Majul le acota: "No siempre una decisión artística implica un acto de censura".

- Para tranquilidad de la República, Majul reapareció en el canal de cable La Nación, recién incorporado a la grilla de Multicanal. Acompañado por talentos como Federico Andahazi (ya no sigue viajando en su costosa moto por los caminos de canal 7) y el economista Martín Tetaz. Un canal que estéticamente no aprovecha la tecnología y que parece una cinta permanente de personas hablando.

- $\quad$ Desde la pantalla de C5N no ayuda a la tranquilidad social el video de Tomás Méndez sobre chiquitos italianos con gritos desgarradores frente a la muerte de sus padres. Mostrando los ataúdes. No era necesario.

- Se escuchó durante décadas aquello de "¿por qué el Estado tiene que solventar al cine?". Siempre presentándolo como algo superfluo, casi innecesario. Frente a la pandemia se multiplican los links para descargar películas gratis. Se revaloriza un arte tan necesaria para ni más ni menos entender el mundo. Son bienvenidas las recomendaciones, pese al comentario ácido de que para ver todas esas películas haría falta una cuarentena de cinco años.

- $\quad$ Es bueno leer a Stephen King, aunque no se aconseja la lectura de "La niebla" en estos días. Tampoco es el mejor momento para darle una oportunidad a "The walking dead".

- $\quad$ El Prode ya no existe más, pero algo muy parecido sucede cuando se anuncia que se extiende la cuarentena y vemos la ansiedad de muchos periodistas para determinar cuánto más durará luego de ese plazo.

- Es un momento interesante para el desafío intelectual de pensar el mundo. Son muchos los interrogantes, algunos ensayan respuestas, realmente no se sabe lo que va a 
pasar. Hacemos fuerza para que Slavoj Zizek tenga razón pero... nunca viene mal recordar a David Viñas que decía "hay que estar atentos al elitismo, a ese 'yo soy el que entiende'. Yo no soy el que entiende, soy el que pregunta, el que se autocuestiona".

Como las columnas no se construyen solos, sino que el pensamiento siempre es dialogado y configurado en conjunto, sigue en estas grageas mi compañero.

4. Último Momento

Andrés Caetano

- "ÚLTIMO MOMENTO" dice el graph en el canal de noticias, los y las conductores miran serios, y dicen que es inminente un anuncio muy importante, lo repiten y enfatizan "muy importante". Le dan la palabra a una columnista que vuelve a decir que sí que son inminentes los anuncios del gobierno, nuevas medidas económicas. Los minutos pasan y pasan. El "ÚLTIMO MOMENTO" ya no parece ni tan momento ni tan último. Entonces llega el anuncio: "Vamos a la publicidad y después les contamos las noticias.

- El maestro Jesús Martín Barbero nos decía en un artículo que "dedicados a fabricar presente, los medios masivos nos construyen un presente autista, esto es que creen poder bastarse a sí mismo. ¿Qué significa esto? En primer lugar, que los medios están contribuyendo a un debilitamiento del pasado, de la conciencia histórica, pues al referirse al pasado, a la historia, casi siempre lo descontextualizan, reduciéndolo a una cita, y a una cita que no es más que un adorno para colorear el presente con lo que alguien ha llamado «las modas de la nostalgia»" Pero ojo, porque el presente también es inmenso.

- ¿Son las redes sociales ese espacio donde se construyen los presentes? ¿Qué presentes construyen? ¿Qué lugar ocupan los medios tradicionales en la agenda informativa? Preguntas que la pandemia mundial y el distanciamiento social nos deja. El Derecho a la comunicación sigue siendo un problema.

5. Nota al pie

El intercambio seguirá, casi performatico, con citas desordenadas pero necesarias, con imágenes compartidas, con reflexiones inmediatas, con entusiasmo, con responsabilidad, con asombro, como Gretel Adorno y Walter Benjamin (1930-1940) como necesidad de comprender el campo simbólico en estos días. 
O como dice el Chino (Vallina) al inicio, parafraseando a Mario Goloboff, nuestras visiones llegan hasta acá y seguirán expandiéndose. No somos previsores/as, ni anticipadores/as, ni mucho menos vaticinadores/as de sociedades nuevas. El neoliberalismo no es homogéneo, el capitalismo tampoco, la subjetividad es histórica, como la conciencia social, como las condiciones culturales de un pueblo. 